\section{Commentary: Should we freeze the elephant trunk with or without stents?}

\author{
François Dagenais, MD
}

In this issue of the Journal, Neri and colleagues ${ }^{1}$ report their experience of arch replacement using their institutionally developed multibranch collared elephant trunk (ET) graft, known as the Siena graft. Between 2002 and 2020, arch replacement with the Siena graft was performed in 146 patients, including $37.6 \%$ with either an acute or a chronic dissection and $62.3 \%$ with diffuse aneurysmal disease. The 30-day mortality was $10.9 \%$, the stroke rate was $5.4 \%$, and paraplegia was seen in 1 patient $(0.6 \%)$. Eleven patients died before the second-stage procedure. The second-stage operation was performed using an open surgery approach in 16 patients $(14.2 \%)$ and an endovascular approach in 97 patients $(85.8 \%)$. Among the patients undergoing endovascular second-stage completion, $72(74.2 \%)$ were treated with standard straight stent grafts, using a single unit in 30 patients, with a total mean aortic coverage length of $182 \mathrm{~mm}$ (range, 154-214 mm). The rate of paraplegia in the patients with second-stage thoracic endovascular aortic repair (TEVAR) completion with branch grafts was comparable to that in patients operated on with an open approach but significantly higher than that in patients treated with a straight TEVAR.

The ET concept as proposed by Borst and colleagues ${ }^{2}$ in 1983 was designed to facilitate a second-stage procedure by avoiding circulatory arrest and minimizing nerve injury during the second-stage descending aortic replacement.

\footnotetext{
From the Department of Cardiac Surgery, Institut Universitaire de Cardiologie et de Pneumologie de Québec, Université Laval, Québec, Québec, Canada.

Disclosures: Dr Dagenais serves as a consultant and proctor for Cook Medical, Edwards Lifesciences and Medtronic.

The Journal policy requires editors and reviewers to disclose conflicts of interest and to decline handling or reviewing manuscripts for which they may have a conflict of interest. The editors and reviewers of this article have no conflicts of interest.

Received for publication Dec 13, 2020; revisions received Dec 13, 2020; accepted for publication Dec 18, 2020; available ahead of print Dec 25, 2020.

Address for reprints: François Dagenais, MD, Institut Universitaire de Cardiologie et de Pneumologie de Québec, 2725 Chemin Sainte-Foy, Québec, Québec, Canada G1V 4G5 (E-mail: francois.dagenais@chg.ulaval.ca).

JTCVS Techniques 2021;6:28-9

2666-2507

Copyright (c) 2020 The Authors. Published by Elsevier Inc. on behalf of The American Association for Thoracic Surgery. This is an open access article under the CC BY-NCND license (http://creativecommons.org/licenses/by-nc-nd/4.0/).

https://doi.org/10.1016/j.xjtc.2020.12.017
}

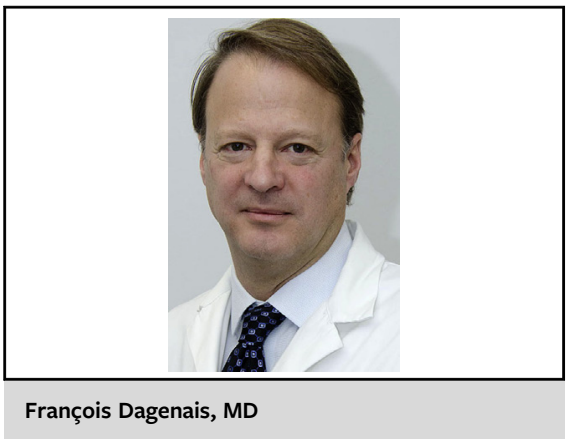

CENTRAL MESSAGE

The Siena multibranch collared elephant trunk graft should be part of the surgeon's armamentarium to treat extensive pathologies of the thoracic aorta.

However, early ET series reported $10 \%$ interval rupture before the second stage and only $45 \%$ of patients undergoing the planned second stage. ${ }^{3}$ The addition of the collar, as in the Siena graft, may decrease early interval rupture by reducing the tension on the anastomosis, especially in the presence of a large discrepancy between the ET graft size and the arch diameter. The advent of TEVAR greatly facilitated second-stage completion either through an antegrade approach during the index procedure as proposed by the Siena group or through a retrograde access during the same hospital stay. Although morbidity and mortality are significantly decreased with a second-stage TEVAR approach compared with an open procedure, paraplegia rates remain similar and of concern, especially with extensive coverage of the thoracoabdominal aorta using endovascular branch grafts. Furthermore, technical issues such as cannulation of a free-floating ET, need for a body floss technique, or kinking of the ET graft may complicate the second-stage endovascular procedure.

The development of frozen ET (FET) grafts has allowed for a single-stage repair of pathologies extending to the mid-descending aorta. Moreover, FET procedures have been shown to secure hemostasis of the distal anastomosis and offer optimal remodeling of the distal aorta after type A dissection repair. However, compared with the $2 \%$ rate of paraplegia with a standard ET procedure, paraplegia in FET repairs is reported in up to $8 \%$ to $10 \%$ of cases, especially when the stent graft extends distal to T8. ${ }^{4}$ Thus, in patients with disease extending distal to the middescending aorta, an ET strategy as proposed by the Siena 
group followed by a second-stage endovascular completion is usually recommended. In addition, current commercially available FET grafts offer a limited range of diameters to treat complex pathologies, such as degenerative chronic dissection after type A repair. In such circumstances, the stent-graft diameter is often oversized for a small true lumen. By snaring and pulling a standard nonstented ET more distal in the true lumen, as illustrated in a few cases in the current report, may efficiently remodel the distal aorta and obviate the problem of an oversized stented graft in a small true lumen. New emerging custom-designed FET devices may adjust to variable anatomies and extend the FET concept to small true lumens or larger-diameter aortas. ${ }^{5}$

In conclusion, Neri and colleagues must be congratulated for their excellent clinical outcomes. As for FET grafts, the Siena graft should be part of the expanding toolbox for surgeons dealing with extensive pathologies of the thoracic aorta. Future graft development and operative strategies will strive to decrease the mortality and morbidity linked to these complex procedures.

\section{References}

1. Neri E, Muzzi L, Tucci E, Cini M, Barabesi L, Tommasino G, et al. Arch replacement with collared elephant trunks: the Siena approach. J Thorac Cardiovasc Surg Tech. 2021;6:13-27.

2. Borst HG, Walterbusch G, Schaps D. Extensive aortic replacement using "elephant trunk" prostheses. Thorac Cardiovasc Surg. 1983;31:37-40.

3. Lus F, Hagl C, Haverich A, Pichlmaier M. Elephant trunk procedure 27 years after Borst: what remains and what is new? Eur J Cardio Thorac Surg. 2011; 40:1-12.

4. Chu MWA, Losenno KL, Dubois LA, Jones PM, Ouzounian M, Whitlock R, et al; Canadian Thoracic Aortic Collaborative (CTAC) Investigators. Early clinical outcome of hybrid arch frozen elephant trunk repair with Thoraflex hybrid graft. Ann Thorac Surg. 2019;107:47-53.

5. Chauvette V, Demers P, Lachapelle K, Chu MWA, Dagenais F. First-in-human use of the Cook hybrid frozen elephant trunk graft: the Canadian experience. Ann Thorac Surg. October 12, 2020 [Epub ahead of print]. 